\title{
Making isotopes matter: Francis Aston and the mass-spectrograph
}

\section{Jeff Hughes}

Centre for the History of Science, Technology and Medicine. University of Manchester. jeff.hughes@manchester.ac.uk

Dynamis

[0211-9536] 2009; 29: 131-165
Fecha de recepción: 22 de febrero de 2008

Fecha de aceptación: 23 de julio de 2008

SUMMARY: 1.-Introduction. 2.-From bottlewasher to gentleman-researcher: Francis Aston at the Cavendish laboratory. 3.-Negotiating the nuclear atom: Rutherford, Bohr and Soddy. 4.-From positive rays to mass-spectrograph: Aston and the element of surprise. 5.-Rutherford, Aston and the constitutive role of the mass-spectrograph. 6.-The Nobel Prizes and the history of isotopes. 7.-Conclusion.

ABSTRACT: Francis Aston «discovered» the isotopes of the light elements at the Cavendish Laboratory in 1919 using his newly devised mass-spectrograph. With this device, a modification of the apparatus he had used as J.J. Thomson's lab assistant before the war, Aston was surprised to find that he could elicit isotopes for many of the elements. This work was contested, but Rutherford, recently appointed to head the Cavendish, was a strong supporter of Aston's work, not least because it supported his emergent programme of research into nuclear structure. This paper will explore Aston's work in the context of skilled practice at the Cavendish and in the wider disciplinary contexts of physics and chemistry. Arguing that Aston's work was made significant by Rutherford - and other constituencies, including chemists and astrophysicists - it will explore the initial construction of isotopes as scientific objects through their embodiment in material practices. It will also show how the process of constructing isotopes was retrospectively reified by the award to Aston of the 1922 Nobel Prize for Chemistry.

PALABRAS CLAVE: Espectrógrafo de masas, Francis Aston, J.J. Thomson, Frederick Soddy, Premios Nobel, isótopos, laboratorio Cavendish.

KEY WORDS: Mass-spectrograph, Francis Aston, J.J. Thomson, Frederick Soddy, Nobel Prizes, isotopes, Cavendish laboratory.

«I will now read to you the state of affairs as it will doubtless be recorded by the historian of the future. In 1914 orthodox chemists were faced with a crisis of unprecedented gravity. Their centenarian ruler, the venerable Postulate of Dalton, was lying dangerously ill with lead poisoning and one 
of their brightest young protégés, Neon, a member of that most exclusive and aristocratic group known as the Noble gases, was strongly suspected of leading a double life» ${ }^{1}$.

«I must say the sort of legend that grows up in connection with the history of discoveries in our own time with which we are completely familiar makes one hesitate to believe there can be any truth in history as recorded by the historian at all, a thought that explains much (...) So easy is it to fall into the error of thinking that things which look obvious after a discovery were just as obvious before» ${ }^{2}$.

\section{Introduction}

In early December 1922, after weeks of worry about travel arrangements and top-hats, the Oxford chemist Frederick Soddy and the Cambridge physicist Francis Aston sailed from Newcastle for Bergen, Christiania and Stockholm. Accompanied by Soddy's wife and Aston's two sisters, they were en route to the glittering annual Nobel Prize ceremony to receive the 1921 and 1922 Nobel Chemistry Prizes respectively. On an icy 10 December, they sat stiffly on the platform in Stockholm's Musical Academy. Following a performance of Sibelius' Elégie, they duly received their awards from King Gustav. For the reserved 1921 Prize, Soddy was cited for «his contributions to our knowledge of the chemistry of radioactive substances, and his investigations into the origin and nature of isotopes». For the 1922 award, Aston was commended «for his discovery, by means of his mass-spectrograph, of isotopes in a large number of non-radioactive elements, and for his enunciation of the whole-number rule». The awards have been taken by many, then and since, as the final and conclusive act in the drama constituting the discovery of the isotopic nature of the elements, the apparent solution to the century-old conundrum of non-integral atomic weights. As H.G. Söderbaum, Secretary of the Swedish Academy of Sciences put it, «with the theory of isotopes

1. F. W. Aston papers. Cambridge University Library. MS Add.8322, unnumbered and undated pencil fragment.

2. Soddy, F. to Noyes, W.A. 22 February 1936. F. Soddy papers. Bodleian Library, Oxford. f. 233. 
one can say with Hamlet: "this was sometime a paradox, but now the time gives it proof" ${ }^{3}$.

For Aston, his sister Helen later recalled, the call to Stockholm was «like a fairy story in which all good things came true, for him the pride of achievement, and for us reflected glory in a measure of which we had never dreamed (...) Stockholm has been the city of our dreams ever since, set in a place apart from anywhere else in all our memories» ${ }^{4}$. Certainly, the scale of the achievement was magnificent, and Soddy and Aston kept elevated intellectual company: at the same Stockholm ceremony, Niels Bohr received the 1922 Nobel Physics Prize while Albert Einstein was cited for the reserved 1921 Physics award. Yet there are reasons to suppose that Helen Aston's remarks were more than affected modesty on her brother's behalf. Ernest Rutherford, head of the Cavendish Laboratory in Cambridge, leading radioactivist and Aston's mentor and promoter betrayed his confusion after the award announcements when he told his confidant Bohr that «Aston's success was of course very satisfactory but I was a little surprised for I [know] Soddy - he must appear necessarily - I had not noticed they had two years 'Chemistry' to fill up as well as Physics» ${ }^{5}$. Himself Nobel Prizeman in Chemistry in 1908 for his work in radioactivity and a leading player in the politics of the new subject, Rutherford had nominated his erstwhile co-worker Soddy several times for the Chemistry award since 1918, but had never nominated Aston and clearly did not see his Cambridge colleague as a Nobel Prize candidate. Rather, Rutherford regarded Aston as a diligent and assiduous experimentalist with considerable practical skills but little conceptual insight into atomic physics. In one sense, it is the surprise shown by Aston, his sister and Rutherford towards Aston's Nobel award which is the subject of this paper.

Some Nobel awards have occasioned enduring controversy among both historians and scientists. The 1923 Physiology-Medicine Prize, for example, has long been surrounded by debate over the precise role of cowinner J.J.R. Macleod in the discovery of insulin and the correctness of the

3. Söderbaum, H. G. Presentation Speech to F. Soddy. In: Nobel Lectures in Chemistry, 1901-1921. Amsterdam-London-New York: Elsevier; 1966, p. 367-370 (369).

4. Aston, Helen, quoted in Hevesy, G. Francis William Aston. Obituary Notices of Fellows of the Royal Society. 1948; 5: 635-650 (645).

5. Rutherford, Ernest to Bohr, Niels. 20 November 1922. Ernest Rutherford papers. Cambridge University Library. MS Add.7653. 
Nobel Institution's decision ${ }^{6}$. Surprise, however, does not figure large in the recent historiography of the Nobel Prizes. Elisabeth Crawford has amply demonstrated the importance of academic politics, professional networks, personal ambitions and animosities, and the ideologies of nationalism and internationalism in framing Nobel science prize decisions, as well as the impact of the awards on the public and the scientific community ${ }^{7}$. Crawford and Robert Marc Friedman have also demonstrated the importance of the Swedish academic context in defining the scope of the science prizes and the disciplinary politics of the Nobel Committees charged with selecting nominators and evaluating nominations for the Nobel awards ${ }^{8}$. From this work, it is clear that Stockholm physical chemist Svante Arrhenius was the éminence gris behind the Nobel physics and chemistry prizes in the first decade of the twentieth century, particularly his role in preferentially promoting atomic research and (paradoxically) in preventing the award of a Prize to Walther Nernst for many years. Indeed, Arrhenius was a key player in the disciplinary discussions bridging chemistry and physics which underlay the award of the 1908 Nobel Chemistry Prize to Rutherford ${ }^{9}$. In that sense, the historiography of the Nobel science prizes overlaps significantly with the historiography of atomic research in the early twentieth century.

Despite this work on the ideology and politics of the Nobel Prizes, however, there is little explicit work on the ways in which the Prizes have interacted with and helped shape the scientists and the sciences they nominally reward. Even in the 1930s, one physicist - a fluid dynamicist - complained that the Nobel Prizes contained a self-perpetuating bias towards

6. Broad, William. Toying with the Truth to Win a Nobel. Science. 1982; 217: 1120-1122.

7. Crawford, Elisabeth. The beginnings of the Nobel Institution. The Science Prizes, 1901-1915. Cambridge: University Press; 1984; Crawford, Elisabeth. Nationalism and internationalism in science, 1880-1939. Four studies of the Nobel population. Cambridge: University Press; 1992.

8. Crawford, Elisabeth; Friedman, Robert Marc. The Prizes in Physics and Chemistry in the context of Swedish science. In: Bernhard, C. G.; Crawford E.; Sörbom, P., eds. Science, technology and society in the time of Alfred Nobel. Oxford: Pergamon Press; 1982, p. 311-331. Friedman, Robert Marc. Nobel Physics Prize in Perspective. Nature. 1981; 292: 793-798; Friedman, Robert Marc. Friedman, Robert Marc Text, context and quicksand: Method and understanding in studying the Nobel Science Prizes. Historical Studies in the Physical and Biological Sciences. 1989; 20: 63-77.

9. Crawford, Elisabeth. Arrhenius, the atomic hypothesis, and the 1908 Nobel Prizes in Physics and Chemistry. Isis. 1974: 75: 503-522; Crawford, Elisabeth. Arrhenius. From ionic theory to the greenhouse effect. Canton, MA: Science History Publications; 1996, p. 233-237. 
«atomic physics», and it has been argued that this bias has persisted to the present ${ }^{10}$. Certainly, in recent popular scientific culture, the linkage between the Nobel science prizes, the reductionist project in twentieth century science, priority and, not least, scientific ego, has been a strong one, naturalised by Gary Taubes» Nobel Dreams and other accounts ${ }^{11}$. In this context, it is perhaps not surprising that historians have paid such scant attention to the 1921 and 1922 Nobel Chemistry awards. Typically, they have seen them as the appropriate reward for a sequence of selfevident scientific achievements beginning with Soddy's articulation of the principle of isotopy for the radioactive elements in 1913, and culminating with Aston's demonstration of the ubiquity of isotopy in the periodic table in 1919 and 1920.

In many ways, this lack of critical analysis is typical of a received historiography which frames the history of early twentieth-century atomic and nuclear physics as a linear, teleological sequence usually beginning with the discovery of x-rays in 1895 and leading through the discovery and elaboration of radioactivity, the discovery of the electron, the articulation of the nuclear theory of the atom, wave mechanics, the discovery of the neutron, artificial radioactivity to nuclear fission. The end-point towards which this sequence extends is the atomic bomb, and it is the phenomena of nuclear weapons and nuclear power which invest this history with its meaning and significance. In this canonical and essentially retrospective account, the discovery of isotopes mark a significant point because of their role in «clarifying» nuclear structure and, of course, because of the later significance of isotopes in the release of nuclear energy ${ }^{12}$.

Faced with such a powerful material vindication of the received historical account, historians have been loath to delve more deeply and offer more critical accounts of the historical development of nuclear science. This

10. Batchelor, George. The life and legacy of G. I. Taylor. Cambridge: Cambridge University Press; 1996, p. 185.

11. Taubes, Gary. Nobel dreams: Power, deceit and the ultimate experiment. New York: Random House; 1986; Singh, Rajinder; Riess, Falk. The 1930 Nobel Prize for Physics: A close decision? Notes and Records of the Royal Society of London. 2001; 55 (2): 267-283. See also the treatment of the Nobel Physics Prize in Kragh, Helge. Quantum generations. A history of Physics in the twentieth century. Princeton: Princeton University Press; 1999, p. 427-439.

12. For a development of this argument, see Hughes, Jeff. Radioactivity and Nuclear Physics. In: Nye, M. J., ed. The Cambridge History of Science. Vol. 5. Modern physical and mathematical sciences. New York: Cambridge University Press; 2002, p. 350-374. 
reticence - one might even say complacency - has significant implications for our understanding of the Nobel Prizes, for in the fields of atomic and nuclear physics and chemistry, Nobel awards can appear in this teleological perspective as ratifications of well-defined and self-evident achievements. The emergence of the isotope interpretation of matter has come to be seen by scientists and historians alike as the correct solution to the long-standing problem of non-integral atomic weights and the outcome of several years of work in which Aston's experimental work «affirmed» and generalised a particular conception of matter put forward by Soddy. ${ }^{13}$ In this paper I argue for a much more interpretative and open-ended historical approach both to the sequence of events which by 1922 had come to constitute the «discovery» of isotopes and to the awards of Nobel Prizes to their «discoverers». Against the canonical account, I suggest that the isotope interpretation of matter as developed by Soddy to explain particular phenomena in radiochemistry was deliberately and contingently linked by him to results emerging from the quite distinct area of gas-discharge research in an effort to make his «isotopes» more plausible. This contingent accomplishment in turn became intimately bound up with the elaboration of the Rutherford-Bohr nuclear model of the atom from 1913. By following Aston's career trajectory from 1913 to 1922, I shall then show that, though a gifted experimentalist, Aston allowed his work to be appropriated by others to support their own theories, and that he, in turn, used those theories to legitimate and give meaning to his own work. In 1919, when Aston created his mass-spectrograph, he was surprised at the nature and quantity of the results it produced: those results were interpreted by others in terms of the nuclear atomic theory, and Aston fell in with this interpretation, adopting it as his own.

For a wide scientific public in the early 1920s, Aston became closely identified not just with the mass-spectrograph and its experimental products - ever-increasing numbers of isotopes of the light elements- but with the nuclear model of the atom promoted by Rutherford's Cavendish. In his influential 1922 monograph Isotopes, Aston promulgated an account in which he endowed isotopes with a pre-history beginning with Prout, and now squarely explained his work in terms of the nuclear atom. When the Nobel Chemistry Committee made their decision in 1922 to make awards

13. Bruzzaniti, G.; Robotti, N. The affirmation of the concept of isotopy and the birth of mass spectrography. Archives Internationales de I'Histoire des Sciences. 1989; 39: 309-334. 
to Soddy and Aston, they were ratifying not just the «discovery of isotopes» but also the nuclear theory of the atom which both offered a rationale for the existence of isotopes and, paradoxically, drew on isotopes for proof of its validity. Moreover, I argue that the Nobel Prize citations themselves aided and abetted a thoroughly retrospective reading of Aston and Soddy's achievements, for they carefully historicise the work of the recipient, usually framing it in a long timescale and making it seem the inevitable outcome of the subject's work. In framing the 1921 and 1922 Chemistry awards, the Nobel Committee not only powerfully intervened to endorse and promote a particular conjunction of theoretical and experimental work, but created a particular form of historical account to achieve a discursive closure. In conclusion, I shall question the notion of authorship in scientific discovery and explore the paradox raised by the award of a Nobel Prize to a person for someone else's interpretation of their work and, I hope, raise searching questions about the nature of scientific achievement and the role of the Nobel Prizes in promoting it.

\section{From bottlewasher to gentleman-researcher: Francis Aston at the Cavendish laboratory}

In order to understand the Nobel Chemistry committee's violation of history and Rutherford's surprise, we must understand something of Francis Aston's background. Born in 1877 into a well-off Birmingham family, Aston had studied physics and chemistry at Mason College, Birmingham, under John Poynting, William Tilden and Percy Frankland. Alongside his studies he pursued private «research» in a makeshift workshop and laboratory at his father's house, becoming an «accomplished, if self-taught experimenter and a skilled glass-blower» ${ }^{14}$. Following the sensational discovery of X-rays, Aston became interested in gas-discharge experiments and X-ray tubes. Aided by books like Salomon's popular Experiments with Vacuum Tubes he began to research intensively on high-vacuum physics using a Sprengel pump and a home-wound X-ray coil. After a period working in a Wolverhampton brewery, during which he continued to work on gas discharges in his spare time with an automatic Töpler pump of his own design, Aston

14. Feather, N. Aston, Francis William. DNB 1941-1950, p. 24-26 (24). 
returned to Birmingham University (as Mason College had now become) with an Associateship of the Institute of Chemistry research scholarship, and spent the next five years making «sound, if unhurried progress» on gas discharges ${ }^{15}$.

Aston arrived at the Cavendish Laboratory in January 1910 to take up a post as research assistant to the then director, J.J. Thomson. Following his elaboration of the negative corpuscle of electricity in 1897 and after, increasingly by 1910 regarded as the "discovery of the electron», Thomson was then engaged on a series of experiments on positive rays in gas discharges, designed to elucidate the nature and character of positive electricity ${ }^{16}$. In practice, however, the experiments had been deeply troublesome, even with the assistance of Ebenezer Everett and Aston's predecessor George Kaye. Aston brought his subtle technique and manipulative skills to bear on Thomson's experiments. As Isobel Falconer has shown, the hallmark of Aston's work was perseverance and the systematic, goal-directed modification of a single experimental design or piece of apparatus in order to obtain definite, stable and reproducible effects ${ }^{17}$. As part of this trial-and-error approach to experimentation, Aston introduced a series of modifications to Thomson's apparatus, allowing characteristic positive rays to be elicited and photographically recorded for every atomic species in the discharge bulb ${ }^{18}$. Following this achievement, Thomson began to see in the slender photographic traces which could now be obtained «a valuable means of analysing the gases in the tube and determining their atomic weights» ${ }^{19}$.

15. Feather, n. 14, p. 25.

16. For recent discussions of the negative corpuscle and the «discovery» of the electron, see Falconer, Isobel. Corpuscles, electrons and cathode rays: J. J. Thomson and the «Discovery of the Electron». British Journal for the History of Science. 1987; 20: 241-276.

17. Falconer, Isobel. Theory and experiment in J. J. Thomson's work on gaseous discharges [Ph.D. Dissertation]. University of Bath; 1985, p. 106-113; Falconer, Isobel. J.J. Thomson's work on positive rays, 1906-1914. Historical Studies in the Physical Sciences. 1988; 18: 265-310.

18. Thomson, J. J. A New method of chemical analysis. Notices of the Proceedings of the Royal Institution. 1911;20: 140-148; Thomson, J. J. Application of positive rays to the study of chemical reactions. Proceedings of the Cambridge Philosophical Society 1911; 16: 455; Thomson, J. J. Further experiments on positive rays. Philosophical Magazine. 1912; 24: 209-253; Thomson, J. J. Rays of positive electricity. London: Longmans, Green \& Co.; 1913.

19. Thomson, J. J. Rays of positive electricity. Philosophical Magazine. 1910; 20: $752-767$ (758). 
With Aston, then, Thomson developed the positive-ray technique as a method of chemical analysis ${ }^{20}$. In 1912, using their «positive ray spectrograph», Aston and Thomson found that neon, the rare gas discovered only a decade or so earlier by William Ramsay, yielded not one but two positive ray traces, corresponding to atomic weights of 20 and $22^{21}$. Thinking that they had discovered a new element, which they christened «meta-neon», apparently after a new element predicted by the theosophists Annie Besant and Charles Leadbeater in their 1908 book Occult Chemistry, Aston embarked upon a series of attempts to separate the new element from neon ${ }^{22}$. Having taken his B.A. by research in 1912, he now began working semiindependently on this project of his own, while J.J. Thomson continued his investigations of the rarer species found in the positive-ray spectrograph, particularly the unusual « $\mathrm{X}_{3} »$. Characteristically, Aston's project was highly empirical. Using fractional distillation and diffusion methods, he sought to separate neon and its heavier congener. He reported his results at the annual meeting of the British Association for the Advancement of Science in Birmingham in September 1913, presenting evidence to show that «atmospheric neon is not homogeneous, but consists of a mixture of two elements of approximate atomic weights 19.9 and 22.1 respectively». The lighter of these was true neon, the heavier the new gas meta-neon, present in atmospheric neon to between 10 and 15\%. Aston concluded that he had «a very strong case for the view that atmospheric Neon is not an element but a mixture of two» ${ }^{23}$.

I want here to emphasise the significance of Aston's claim to have discovered a new element. In addition to the remarkable role of Besant and Leadbeater's Occult Chemistry in providing the conceptual resources to interpret the new neon trace and to bring «meta-neon» into laboratory culture, the idea that atmospheric neon might consist of yet further «hidden»

20. Aston, F. W. Sir J. J. Thomson's new method of chemical analysis. Science Progress. 1912; 7: 48-65.

21. On the background to the discovery of the rare gases, see Hirsh, R. F. A Conflict of principles: The discovery of Argon and the debate over its existence. Ambix. 1981; 28: 121-130.

22. Aston, F. W. On the homogeneity of atmospheric Neon. Unpublished and undated typescript. Aston papers. Almost certainly Aston's paper to the British Association for the Advancement of Science, 1913. Besant, Annie; Leadbeater, Charles. Occult chemistry: A series of Clairvoyant observations on the chemical elements. London: Theosophical Publishing House; 1908, p. 83.

23. Aston, n. 22, p. 11-12. 
elements was a credible one. Like the other «noble» gases, neon itself had only been discovered a decade or so earlier on the basis of subtle physical measurements, and had been accommodated by extending the periodic table to create a new group. It was entirely plausible to suppose that further elements might be found, perhaps using the even more subtle traces of the positive-ray spectrograph. The difficulty with this view, however, was that conventional spectroscopic analysis failed to show a distinct optical spectrum for the new gas. By 1913 the spectroscope was, according to Aston, «an instrument which until very lately, has been regarded not only as the most prolific source of the discovery of new elements but also as an infallible means of their identification» ${ }^{24}$. Its inability to adjudicate in the neon case was not irreparable, however; Aston put forward two possible explanations to account for the spectroscope result: «Either Metaneon is a gas like Oxygen of which the spectrum is easily swamped and can only be brought out in the absence of preponderating quantities of other gases; or its spectrum is identical with that of Neon». The first explanation appealed to precedent and spectroscopic practice; the second he regarded as «fundamental and revolutionary» 25 .

Aston had not arrived at this second suggestion unaided: he noted that «I am informed by Mr. N. Bohr that on certain aspects of the Nucleus Atom theory of Rutherford, he is led to the conclusion that if Metaneon exists its spectrum not only may, but of necessity must be identical with that of Neon» ${ }^{26}$. Aston's invocation of Bohr is highly significant, and to understand it we must now turn to developments elsewhere which provided resources for Aston to reframe and reinterpret his work and link it concerns out with the Cavendish Laboratory.

\section{Negotiating the nuclear atom: Rutherford, Bohr and Soddy}

In 1912, it had been reported that two radioactive elements, ionium and thorium, virtually inseparable from each other by chemical means, also displayed identical spectra. It was in an effort to explain such complexities that Rutherford's former co-worker Frederick Soddy, then Lecturer in Ra-

\footnotetext{
24. Aston, n. 22, p. 12.

25. Aston, n. 22, p. 12-13.

26. Aston, n. 22, p. 12-13.
} 
dioactivity at Glasgow University and increasingly a populariser and essayist on matters radioactive, put forward his hypothesis of «isotopic elements» or «isotopes». Isotopes, according to Soddy, «occupy the same place in the periodic table, and are chemically indistinguishable. This material identity, however, extends far beyond the chemical properties in the narrow sense, and embraces probably nearly all the common physical properties also, so that the experimental means capable of distinguishing and separating isotopes are very limited» ${ }^{27}$. Soddy's concept was formulated to account for the properties of certain radioactive elements, whose characteristics and behaviour were widely regarded as anomalous and exceptional with respect to the rest of the periodic table. Where the isotope hypothesis had been proposed to account for the apparent inseparability of certain pairs of radio-elements, the concept was sufficiently open-ended to allow Soddy, looking to bolster his isotope hypothesis in the face of very considerable opposition from chemists, to appropriate and give new meaning to Aston's results on neon and metaneon. In his comprehensive summary of recent work in radioactivity for the Chemical Society in 1913, he noted with glee that «what appears to be a case of isotopic elements outside the radioactive sequences has been discovered» Ignoring the opposition rapidly mounting against his isotope hypothesis, he trumpeted Aston's results as a «dramatic extension of what has been found for the elements at one extreme of the periodic table, to the case of an element at the other extreme», strengthening the view that «the complexity of matter in general is greater than the periodic law alone reveals» ${ }^{28}$. Moreover, the «nuclear theory of Sir Ernest Rutherford», as he put it later, «dovetailed in nicely» ${ }^{29}$.

While Soddy sought to establish the plausibility of his isotope hypothesis by demonstrating the generality of its application across the periodic table and its links to the nuclear hypothesis, his argument could be put to work in other contexts. The young and relatively unknown Niels Bohr, working with Rutherford at Manchester after his disappointment with J. J. Thomson and Cambridge, had become interested in the structure of the atom and the explanation of radioactivity and spectroscopic phenomena such as series spectra. Taking Rutherford's recently proposed nuclear model of the atom,

27. Soddy, F. Radioactivity. Chemical Society Annual Report on the Progress of Chemistry. 1914; 10: 262-288 (264-265).

28. Soddy, n. 27, p. 265-266.

29. Soddy, F. Discussion on isotopes. Proceedings of the Royal Society. 1921; 99: 87-104 (99). 
Bohr created a new synthesis which similarly attempted to generalise from radioactive phenomena to the whole periodic table:

«As is well known, several of [the radioactive substances] have very similar chemical properties and have hitherto resisted every attempt to separate them by chemical means. There is also some evidence that the substances in question show the same line spectrum. It has been suggested by several writers that the substances are different only in radio-active properties and atomic weights and identical in all other physical and chemical respects. According to the [Rutherford] theory this would mean that the charge on the nucleus, as well as the configuration of the surrounding electrons, was identical in some of the elements, the only difference being the mass and the internal constitution of the nucleus» ${ }^{30}$.

While Bohr's model was designed to account for the nuclei of heavy, radioactive elements, it was in principle capable of extension to the lighter elements. The neon case provided exactly the grounds for such and extension.

It was at the BAAS meeting in 1913 that a new synthesis began to emerge, a self-reinforcing combination of three recent developments: $\mathrm{Ru}$ therford's still-speculative nuclear atom, Bohr's elaboration of its implications and possibilities, and Soddy's equally speculative theory of isotopes. Each element supported and, in a sense, legitimated the others. Indeed, Bohr began to cite the neon case as a paradigmatic example of isotopy in the light elements and therefore an important argument in favour of the nuclear theory. The circularity in the argument was evident, however, in his claim in one lecture that the isotope hypothesis was both a «necessary consequence and simultaneously "proof» of Rutherford's theory» ${ }^{31}$. Rutherford, too, saw the possibilities in the neon results and followed Bohr in suggesting that «this new point of view will result in a systematic examination of all the elements to test for the possible presence of isotopes, and will thus give an additional reason for the accurate determination of

30. Bohr, Niels. Note on the properties of isotopes and the theory of the nucleus atom. In: Rosenfeld, L., ed. Niels Bohr. Collected works. 9 vols. Amsterdam: North-Holland; 1972-1986, vol. 2, p. 418-425.

31. Bohr, Niels. Recent work in atomic theory. Notes for lectures given at the University of Copenhagen, Autumn 1916. In: Rosenfeld; Bohr. n. 30, vol. 8, p. 167-193 (175-176), scare quote in original. 
atomic weights for elements from widely different sources» ${ }^{32}$. This view was further propagated by one of Rutherford's students and acolytes, Edward Andrade, in a 1914 review article for Science Progress which provided an extensive showcase for the Rutherford-Bohr atom. Commenting on the «sensational announcement» of Aston's «separation of a new gas of atomic weight 22» and the apparent identity of its spectrum and chemical properties with those of neon, Andrade noted that «on Rutherford's nucleus atom theory such a state of things is quite possible, since the chemical and physical properties of an atom depend on the charge of the nucleus, while the atomic weight depends on the inner structure of the nucleus and may not be proportionate to the charge» ${ }^{33}$.

While Soddy, Rutherford and Bohr all sought to make Aston's work on neon relevant to their own efforts to promote «isotopes» and the nuclear atom against considerable opposition, Aston was seduced by their interpretations of his work. As he increased his autonomy and his intellectual distance from J.J. Thomson at the Cavendish Laboratory, he now returned the compliment by adopting the interpretation they put on his work, and redefining his research to pursue some of its consequences. In a letter to Joseph Larmor seeking support for a scholarship, he argued that the funds would give him the «opportunity to continue my work on the composition of Neon and also to undertake a piece of research which I certainly think ought to be done. This is a systematic comparison of the atomic masses of all available chemicals by the method of positive rays» ${ }^{34}$. This systematic, almost taxonomic, style of work was absolutely characteristic of Aston. While he adopted the «reductionist» interpretation of his work and allowed it to shape his research plans, the style of that research remained true to that of his earlier work: skilful manipulation of the experimental apparatus to obtain new results which others could interpret. As we shall see, this was a pattern which would continue.

Having secured Larmor's support and with it the prestigious Clerk Maxwell Scholarship at Cambridge, Aston constructed a more elaborate

32. Rutherford, Ernest. The constitution of matter and the evolution of the elements. Two lectures at the National Academy of Sciences, Washington D.C. 21 and 23 April 1914. Rutherford papers. PA108.

33. Andrade, E. N. da C. Physics in 1913. Science Progress. 1914; 8: 608-625 $(608,621)$.

34. Aston, F. W. to Larmor, Joseph. 22 October 1913. Joseph Larmor papers. Royal Society, London. 
diffusion apparatus, which was in operation early in 1914. In order to test the weights of the gaseous fractions, he also designed and built a quartz micro-balance, accurate to $10^{-9} \mathrm{~g}$. In the long summer of that year, it seemed only a matter of time before Aston would be able to make definitive measurements of the masses of the two elements in neon in order to clarify the identity of the heavier element. Soddy, meanwhile, continued to publicise Aston's neon results as evidence of the existence of isotopes among the lighter elements. In doing so, we should note that he deliberately made the Cavendish work relevant and useful to his own research. Moreover, Aston's work and the positive ray technique offered opportunities for the future development of radiochemical practice, for «[f]ractional diffusion is almost the only property that can be expected to effect a partial separation of a group of isotopic elements into their constituents [whilst] to detect the non-homogeneity, if it exists, the new positive ray method of Sir J.J. Thomson is again almost the only one available» ${ }^{35}$.

Not everyone agreed. At the 1914 BAAS meeting in Australia, chemist Henry Armstrong fulminated against the moderns in a joint session of Sections $\mathrm{A}$ and $\mathrm{B}$. He thought it was «doubtful if it be permissible at present to conclude that elements of different atomic weights may and do exist which are indistinguishable chemically», arguing that «[t]he observations on which reliance is placed have been made with quantities of material far too small to permit of such an inference». Attacking the positive ray technique and its products, he concluded that « $[\mathrm{t}]$ hough the special methods made use of by physicists are very powerful, they suffice only in certain cases and have little chemical significance; when physicists resort to chemical methods the work becomes subject to ordinary criteria» ${ }^{36}$. And while chemists (and here he surely spoke for a fair number of physicists too) had to «admire as well as welcome the bold attempt physicists are making to unravel the structure of the elementary atom», their arguments remained «novel and daring» and, by implication, dangerous and unacceptable. Of course, later commentators have seen Armstrong as a hopeless reactionary. Yet his criticisms of radioactivity and the rarefied electrical measurement techniques of the modern physicists were epistemologically powerful, and further work is undoubtedly needed to explore this opposition.

35. Soddy, n. 27, p. 265.

36. Amstrong, Henry. Discussion on the structure of atoms and molecules. Report of the British Association for the Advancement of Science. 1914; p. 293-301 (294). 
After the outbreak of war, with civil research in Britain interrupted for the duration, Aston, like several other Cambridge scientists, went to the Royal Aircraft Factory at Farnborough to undertake research for the nascent Royal Air Force ${ }^{37}$. Billeted with other scientists at a house known as Chudleigh Mess, he had frequent scientific discussions with his colleagues, particularly Frederick Lindemann, who had recently returned to England from Nernst's laboratory in Berlin where he had been working on problems of specific heats. The atmosphere of the mess was that of «a somewhat rowdy Senior Common Room in which violent disputes on abstruse subjects were frequent, the youth of the members preventing too solemn a parade of knowledge» ${ }^{38}$. Among the scientific topics discussed were neon and isotopes. Lindemann was sceptical, and concluded one «hilarious» argument with the jokingly peremptory put-down: «It is not to be expected that you would know anything about the matter because you are only J.J's bottlewasher» ${ }^{39}$. Nevertheless, these conversations resulted in a joint paper with Aston on the possibility of separating isotopes, which appeared in the Philosophical Magazine in 1919. And at the greatly scaleddown BAAS meeting in 1915, Lindemann brought his own strand to the debate by arguing against Bohr that it was «thermodynamically impossible for two substances which differ in atomic weight to be identical in all other properties» ${ }^{40}$.

By April 1919, when Aston left Farnborough and returned to Cambridge, the isotope hypothesis had found additional support through the wartime work of Hönigschmid and others on the slightly different atomic weights of lead from radioactive and non-radioactive sources ${ }^{41}$. Soddy had con-

37. Hevesy, n. 4, p. 640; Birkenhead, Earl of. The prof in two worlds: The official life of Professor F. A. Lindemann, Viscount Cherwell. London: Collins; 1961, p. 59-80.

38. Birkenhead, n. 37, p. 66.

39. Fage, A. Early days. Memories of people and places. Journal of the Royal Aeronautical Society. 1966; 70: 91-92.

40. Lindemann, F. A.; Aston, F. W. The possibility of separating isotopes. Philosophical Magazine. 1919; 37: 523-534; Lindemann, F.A. In Reply to Dr. Bohr's remark in the discussion on isotopes at the meeting of the B.A. 9 September 1915. Cherwell papers. Nuffield College, Oxford.

41. Richards, T. W.; Lembert, M. E. The atomic weight of lead of radioactive origin. Journal of the American Chemical Society. 1914; 36: 1329-1344; Richards, T.W.; Hall, N. F. An attempt to separate the isotopic forms of lead by fractional crystallisation. Journal of the American Chemical Society. 1917; 39: 531-541; Hönigschmid, O. Über das Thoriumblei. Physikalische Zeitschrift. 1917; 18: 114-115; Hönigschmid, O. Über das Thoriumblei. Physikalische Zeitschrift. 1918; 19: 436-437. For a good historical discussion, see Kauffman, G. B. The atomic weight of lead of 
tinued to marshall new evidence and to proselytise for the concept among chemists with characteristic rhetorical élan and vigour, and now sought to enrol atomic weights chemists to his project. In a May 1917 lecture on «The Complexity of the Chemical Elements» at the Royal Institution, London, he reviewed recent work on radiochemistry, isotopes and the nuclear atom, which had «done much to explain the meaning of isotopes and the periodic law». The lead question now took the central evidential role, and Aston's neon and metaneon were not even mentioned. Soddy developed used the idea of isotopes to explain the non-homogeneity of the elements and the occurrence of non-integral atomic weights (using magnesium and chlorine as his examples), and emphasised the importance of reform and cooperation in research on atomic weights. This appeal was clearly successful, for isotopes received a major boost in December 1919 when Harvard chemist Theodore Richards received the 1914 Nobel Chemistry prize awarded to him in 1915 for his work on atomic weights ${ }^{42}$. Having described his own life's work in his Nobel Lecture, Richards turned to the question of lead, and reported his finding that lead from radioactive sources and ordinary lead had different atomic weights. Adopting the language of isotopes, he proposed that scientists must now «study likewise all other elementary substances, in order to find out whether they may have atoms of differing weight», for " $[w]$ ho knows what modifications our Periodic System of the elements may suffer, and what illumination it may gain, from such experiments» Atomic weight research had been given a «new significance» by these recent developments, and was now «far from being a completed and closed chapter of Science». The future opened up «a prospect of almost endless further investigations, because the study of a single kind of material is not enough to make sure of the universality of an atomic weight» ${ }^{43}$.

This was powerful support for Soddy's hypothesis and for those like Rutherford and Bohr who sought to link it to their own concerns. In 1917, Rutherford had nominated Soddy for the Nobel Chemistry Prize «on the ground of his notable original advances to our knowledge of the constitution

radioactive origin: A confirmation of the concept of isotopy and the group displacement laws. In: Kauffman, G. B., ed. Frederick Soddy. Early pioneer in Radiochemistry. Dordrecht: D. Reidel; 1986, p. 67-92.

42. Gay, H. The chemical philosophy of Theodore W. Richards. Ambix. 1997; 44 (1): 19-38.

43. Richards, T. W. Atomic weights. In: Nobel lectures in Chemistry, 1901-1921. Amsterdam: Elsevier; 1966, p. 280-292 (291-292). 
and relation of the Radio-active Elements», including "the transformation theory of the radio-active elements», the «first experimental proof of the production of helium by radium» and the «wide generalisation of the relation between the chemical properties of successive radio-active elements and the type of radiation they emit». "Also», he added as an afterthought, «the general theory of isotopic elements», which had «already been amply verified and has opened up new and fruitful lines of research» ${ }^{44}$. In the event, the 1917 Chemistry Prize was not awarded, but Rutherford's nominee for the Physics Prize that year - British physicist Charles Barkla- received the reserved 1917 award in 1918. Rutherford nominated Soddy again in 1918, 1919, 1921 and 1922. In 1921, his recommendation was more succinct: he nominated Soddy for «his notable contributions to our knowledge of the chemistry of the radioactive bodies and his proof of the nature and existence of isotopes» ${ }^{45}$. We should note carefully that Rutherford attributed sole credit for isotopes to Soddy. We should also note that following Barkla's Nobel award in 1918, Rutherford's new nominee for the Physics Prize in 1919 was none other than Niels Bohr. We shall return to the politics of Nobel Prize nomination in due course.

\section{From positive rays to mass-spectrograph: Aston and the element of surprise}

Shortly after Aston returned to Cambridge in 1919, Rutherford was elected to succeed J.J. Thomson as Director of the Cavendish Laboratory. Rutherford brought with him the programme of research he had developed at Manchester: radioactivity. Following the work of Bohr and his own finding in 1917 that he had apparently released hydrogen particles — «protons»- from nitrogen nuclei by bombarding them with alpha-particles, this programme now also included the composition and structure of the atomic nucleus itself. As Rutherford began to recruit students and to develop his work, Thomson was given space to continue his own work on gas discharges with Everett and a few research students. It was here, in the «garage» that

44. Rutherford, Ernest to Secretary, Nobel Committee for Chemistry. 26 January 1917. Nobel Prize Archives, Royal Academy of Sciences, Stockholm.

45. Rutherford, Ernest to Secretary, Nobel Committee for Chemistry. 10 October 1921. Nobel Prize Archives, Royal Academy of Sciences, Stockholm. 
Aston now resumed his research on neon and meta-neon. He began work on a mechanically-operated diffusion apparatus, with the aim of effecting a more complete separation of the two gases ${ }^{46}$. He complained to Lindemann that the "poor old diffusion apparatus seems to be suffering from a sort of Rheumatical Arthritis in the [sealing wax] joints and has just had to undergo a major operation but I hope it will be mobilized tomorrow» ${ }^{47}$. It proved unworkable, however, so in the summer of 1919, financed by a small sum from the Royal Society's Government Grant Committee, Aston conceived and began to develop another modification of the positive ray apparatus, still in the hope of clarifying the neon issue ${ }^{48}$. With a sufficiently powerful and discriminatory device, he believed he could determine whether the lighter of the two neon parabolas had an atomic weight as high as 20.2 (thereby corresponding to neon's accepted atomic weight), and hence shed light on the character of the two elements. Perhaps drawing upon a modified method of positive-ray analysis developed during the war by Arthur J. Dempster, a Canadian postdoctoral physicist at the University of Chicago ${ }^{49}$, Aston designed a sensitive focussing system with separate electric and magnetic fields, which he hoped would serve to settle the neon question beyond dispute ${ }^{50}$.

By mid-November he had completed the apparatus and had made a series of measurements with neon in the discharge tube. Comparing the masses of the two neon lines with established hydrocarbon calibration lines at masses 12,13,14, 15 and 16, Aston found, to his enormous surprise, that the neon lines corresponded almost exactly to masses 20.00 and 22.00. Following his conversations with Lindemann and the trend of the previous few years» work in radioactivity, he now unequivocally interpreted meta-

\footnotetext{
46. Aston, F. W. to Lindemann. 25 April 1919. Cherwell papers, Nuffield College, Oxford.

47. Aston, n. 46.

48. Aston, F. W. to Lindemann. 14 June 1919. Cherwell papers, Nuffield College, Oxford.

49. Dempster, A. J. A new method of positive ray analysis. Physical Review. 1918; 11: 316-325. Dempster had graduated from Toronto, and had then won an 1851 Exhibition Scholarship to work with Wien, an expert on positive rays, at Wurzburg. He had managed to leave Germany just in time to escape internment in 1914, and had completed his work in Millikan's laboratory at Chicago, graduating summa cum laude in 1916 with the thesis: The properties of slow canal rays. See Allison, S. K. Arthur Jeffrey Dempster, 1886-1950. Biographical Memoirs of the National Academy of Sciences. 1952; 27: 319-333.

50. Aston, F. W. Neon. Nature. 1919; 104: 334; Aston, F. W. A Positive-Ray Spectrograph. Philosophical Magazine. 1919; 38: 707-714.
} 
neon as an isotope of neon ${ }^{51}$. A brief note in Nature on 27 November announced his preliminary findings ${ }^{52}$. It was followed three weeks later by details of more «remarkable results». After his success with neon, Aston had set out to analyse a few other elements. When chlorine was admitted to the machine, the photographic plates obtained showed «at least two isotopes of atomic weights 35 and 37 (...) [whose] (...) elemental nature is confirmed by lines corresponding to double charges at 17.50 and 18.50, and [is] further supported by lines corresponding to the compounds $\mathrm{HCl}$ at 36 and $38{ }^{53}$. Carbon and oxygen appeared to be «pure», while mercury, like neon and chlorine, was of «mixed» character. Elated by this burst of revelations, Aston dashed off a letter to Lindemann ${ }^{54}$ :

«You will probably have seen ere this that my apparatus has been productive of some most astonishing results. I have been living in a state of wild excitement (...) By next week I hope Nature will publish a letter in which I announce the mixed isotopic nature of $\mathrm{Cl}$ and $\mathrm{Hg}$ and most important of all the fact that every single mass yet measured with certainty falls exactly on a whole number».

Aston's surprise is delightful - and very informative. He had hoped definitively to settle the neon question - that, after all, had been the reason for the construction of the new spectrograph. But the wider applicability of the method came as a genuine revelation to him, and to everyone else. Note too that the adoption of the isotope interpretation for neon, the ground for which had been prepared by Soddy, encouraged Aston to extend the concept immediately to the other novel species disclosed by the new machine. In January 1920, helium and hydrogen were submitted to analysis, yielding yet more «very interesting» results. Helium appeared to be a «pure» element of mass 4.00, but hydrogen gave a mass of 1.008 in approximate agreement with that accepted by chemists ${ }^{55}$. By March 1920, a substantial number of

51. There was even the possibility of a third isotope of mass 21, though the line was extremely faint: see Aston, F. W. The constitution of atmospheric Neon. Philosophical Magazine. 1920; 39: 449-455 (455).

52. Aston, F.W. Neon. Nature. 1919; 104: 334.

53. Aston, n. 51.

54. Aston, F. W. to Lindemann. 13 December 1919. Cherwell papers, Nuffield College, Oxford. See also Thomson, G. P. to Lindemann. 12 December 1920. Cherwell papers, Nuffield College, Oxford.

55. Aston, F. W. The constitution of the elements. Nature. 1920; 105: 8. 
the light elements had been successfully analysed ${ }^{56}$. «My apparatus», Aston told Lindemann jubilantly, «is a daisy at isotope production» 57 .

In virtue of the revised arrangement of electric and magnetic field in the modified apparatus, Aston coined the term mass-spectrograph for his new device. Although it was a term which he deployed self-consciously and policed carefully in an attempt to distance himself from Thomson's sphere of influence and the older "positive-ray spectrograph», it was not one whose force was immediately apparent to others, who typically saw Aston's system as a «mere» refinement of the older positive ray method. Aston's attempts to stress the differences between his new technique and the older method were, in part, a response to Thomson's reaction to the flood of new results. Aston told Lindemann, for example, that «Rutherford is most encouraging and so is everyone else except JJT who is apparently extremely annoyed with the whole thing and will hardly look at my negatives at all» ${ }^{58}$. As these remarks suggest, Aston could scarcely have wished for a more sympathetic environment in which to pursue this work than Rutherford's Cavendish Laboratory. There was good reason for Rutherford's benevolence. At precisely this moment, he was struggling to interpret his experiments on the «disintegration» of nitrogen. Aston's work gave him the interpretative resources he needed to do so.

\section{Rutherford, Aston and the constitutive role of the mass-spectrograph}

Throughout the 1920s, one of the elements central to the development of Rutherford's understanding of the nucleus and its structure was the mass-spectrograph. In December 1919, when he first announced the mass-spectrographic analyses of several elements, Aston noted an unusual numerological relation: «A fact of the greatest theoretical interest appears to underlie these results, namely, that of more than forty different values

56. Aston, F. W. The mass-spectra of chemical elements. Philosophical Magazine. 1920; 39: 611-625; Aston, n. 55, p. 547; Aston, F. W. Isotopes and atomic weights. Nature. 1920; 105: 617; Aston, F. W. Mass-spectra and the atomic weights of the elements. Science Progress. 1920; 15: 212222; Aston, F. W. The Mass-spectra of the chemical elements. Part II. Philosophical Magazine. 1920; 40: 628-634; Aston, F. W. Constitution of the elements; Minimum number and mass of isotopes. Nature. 1920; 106: 468.

57. Aston, F. W. to Lindemann. 21 February 1920. Cherwell papers, Nuffield College, Oxford.

58. Aston, n. 57. 
of atomic and molecular mass so far measured all, without a single exception, fall on whole numbers, carbon and oxygen being taken as 12 and 16 exactly (...) Should this integer relation prove general, it should do much to elucidate the ultimate structure of matter» ${ }^{59}$.

In January 1920, Rutherford wrote to one colleague:

«You will have seen in 'Nature' about Aston's work on the isotopic nature of neon, chlorine and mercury. He has greatly developed the positive ray method and I have great confidence in his conclusions. He is a very skilful experimenter and has had much experience with positive rays. You will appreciate what a large field of work this will open up and we may hope before long to decide which elements contain isotopes» ${ }^{60}$.

By February 1920, Aston's apparatus was producing results at an astonishing rate. In the space of two days, eleven elements fell to mass-spectrographic analysis. Aston had told the Cambridge Philosophical Society a few weeks earlier that while helium appeared to be a "pure» element of mass 4.00, hydrogen was "very definitely heavier than unity $(\mathrm{O}=16)$ », thereby constituting the single exception «proving» what he came to call the «whole number rule» 61 . Aston archly offered Lindemann «the latest official quotations for elemental stocks, fractions barred except in the case of Hydrogen» ${ }^{62}$. The significance of the whole-number rule was two-fold. On the one hand it introduced a «very desirable simplification into the theoretical aspects of mass» ${ }^{63}$. On the other, it opened up a new discourse of nuclear energy which was closely linked to Rutherford's account of the constitution of the nucleus. This link with nuclear constitution and Rutherford's speculations about isotopes allowed Aston to «explain» why hydrogen had to be an exception to the whole-number rule, since «on the Rutherford «nucleus» theory the hydrogen atom is the only one not containing any negative electricity in its nucleus» ${ }^{64}$. In fact ${ }^{65}$ :

\footnotetext{
59. Aston, F.W. The constitution of the elements. Nature. 1919; 104: 393.

60. Rutherford, Ernest to Meyer. 13 January 1920. Rutherford papers.

61. Aston, F. W. Cambridge Philosophical Society. Nature. 1920; 104: 714.

62. Aston, F. W. to Lindemann. 21 February 1920. Cherwell papers, Nuffield College, Oxford.

63. Aston, F. W. The Mass-spectra of chemical elements. Philosophical Magazine. 1920; 39: 611-625 (619).

64. Aston, n. 63.

65. Aston, F. W. Isotopes and atomic weights; 1921. Reprinted in: Bragg, L.; Porter, G., eds. Royal Institution Library of science: Physical Sciences. London: Applied Science Publishers; 1970,
} 
«The case of the element hydrogen is unique, for its atom appears to consist of a single proton as nucleus with one planetary electron. It is the only atom in which the nucleus is not composed of a number of protons and electrons packed exceedingly close together. Theory indicates that when such close packing takes place the effective mass will be reduced, so that when 4 protons are placed together with two electrons to form the helium nucleus, they will have a weight rather less than four times that of the hydrogen nucleus, which is actually the case».

«Theory indicates», indeed. Where Rutherford had appropriated Aston's work to sustain his interpretation of the disintegration experiments, Aston now again reciprocated by wholeheartedly deploying the nuclear hypothesis as an interpretative scheme within which to situate and make sense of his results. In his Royal Society Bakerian Lecture in June 1920, Rutherford had diagramatically illustrated the possible composition of various isotopic nuclei. Aston, too, now constructed models of the nuclei of various isotopes. While Rutherford had used protons, electrons and helium nuclei of mass 3 and 4, however, Aston used only protons and electrons, which he referred to as the «standard bricks» of matter ${ }^{66}$. These bricks were so arranged that "[i] $\mathrm{n}$ the nuclei of normal atoms the packing of the electrons and protons is so close that the additive law of mass will not hold and the mass of the nucleus will be less than the sum of the masses of its constituent charges» ${ }^{67}$.

There was a disciplinary pay-off to this reductionist programme. Aston's results, he told a Royal Institution audience, «lie on the border line of physics and chemistry, and although as a chemist I view with some dismay the possibility of eighteen different mercuric chlorides, as a physicist it is a great relief to find that Nature employs at least approximately standard bricks in her operations of element building» ${ }^{68}$. Crucially, the isotope interpretation of matter called for «a drastic revision of conventional ideas regarding the elements» ${ }^{69}$. The fractional weights which had been found by chemists for many of the elements were now to be explained away as «fortuitous statistical effects due to the relative quantities of the isotopic

vol. 8, p. 332-342 (341)

66. Aston, F. W. Isotopes. London: Edward Arnold \& Co.; 1922, p. 97.

67. Aston, n. 66, p. 101. Emphasis in original.

68. Aston, n. 65, p. 342.

69. Aston, F. W. Chemistry at the British Association. Nature. 1920; 106: 358-359, on p. 358. 
constituents» ${ }^{70}$ - what Arthur Smithells, Professor of Chemistry at Leeds University, called «the tidying up of the atomic weights», in which Aston «brushes all the nasty fractions up and puts them into the wastepaper basket afforded by the atom of hydrogen» ${ }^{71}$.

Such an interpretation threatened to undermine decades of careful and painstaking work by atomic weight chemists, however, and Aston was less careful to cultivate chemists than Soddy had been ${ }^{72}$. But there was another point to the model-building. By 1921 it was evident that the non-integral mass of hydrogen and the possibility of a «packing effect» in the formation of «stable assemblages» meant that the energy of the heavier nuclei could be taken as a key indicator of their constitution. Rutherford's most recent experiments had led him to re-conceptualise the nucleus in terms of a «core» of tightly-bound - particles surrounded at a distance by hydrogen outriders or «satellites». Because they were less tightly bound, these satellite protons should increase the mass of the atom slightly, and «we should expect that the whole-number rule found by Aston, which appears to hold for atomic masses to about 1 in 1000, would be departed from if measurements could be made with yet greater accuracy» ${ }^{73}$. In virtue of this it was «of the greatest importance to push the accuracy of methods of atomic weighing as far as possible, for variations from the whole number rule, if they could be determined with precision, would give us some hope of laying bare the innermost of secrets, the actual configuration of charges in the nucleus» ${ }^{74}$.

As Aston's thoughts began to turn to the design and construction of a second, more powerful machine to pursue the finer details of Rutherford's programme of nuclear research, he continued to modify various elements

70. Aston, F. W. The mass-spectra of chemical elements. Philosophical Magazine. 1920; 39: 611-625 (624).

71. Smithells, Arthur to Richards, T. W. 12 November 1920. Arthur Smithells papers, University of Leeds Library.

72. See, for example, Thorpe, T. E. Presidential address. Report of the British Association for the Advancement of Science; 1921, p. 1-24. At the same time, however, isotopes found a large constituency among chemists who attempted to separate and characterise the new species, thereby embodying isotopes in chemical practice; George Hevesy, for example, joked to a friend that he had joined «die Sekte der Isotopentrenner» — the «sect of the isotope-separators». See Levi, H. George de Hevesy: Life and work. Copenhagen: Rhodos; 1985, p. 49.

73. Rutherford, Ernest. Artificial disintegration of the elements. Journal of the Chemical Society. 1922; 121: 400-415 (413)

74. Aston, n. 65, p. 341-342. 
of the mass-spectrograph and his interpretative practice. In June 1922, for example, Rutherford told Bohr that «[t] he laboratory has been in a state of great excitement the last week, due to trying certain new kinds of photographic plates, which one makes in the laboratory. Aston finds them about six times faster and very much clearer for his positive rays» ${ }^{75}$. Photographic plates proved to be crucial to Aston's project: a systematic survey of the isotopes of the elements, much along the lines he had suggested to Larmor back in 1913, but now using the mass-spectrograph. After the first flush of success in 1920, a minor change in the manufacturing process by the Paget Plate Company, proprietary suppliers of photographic apparatus, produced greatly inferior mass-spectra, to Aston's intense dismay. He even commissioned a special batch of plates of the old design from the company so as to be able to continue his investigations in the style to which he had become accustomed. He also began a series of trials of his own on photographic plates. Trial-and-error produced some surprises. Using the specially treated plates Rutherford mentioned - ordinary plates converted into Schumann plates by dissolving away the gelatine- Aston found the results «successful beyond all expectations», revealing new isotopes of tin for the first time - a «lucky accident», as he put it ${ }^{76}$. Clearly, skill and serendipity played equally significant roles in Aston's accomplishments.

It should be clear from the foregoing that even by 1920, a powerfully mutually-reinforcing relationship existed between Rutherford's reductionist programme of nuclear research and Aston's mass-spectrograph and its products. While each contributed significantly to the meaning and scope of the other, it is also clear that in his trajectory from «J.J's bottlewasher» to independent gentleman-researcher, Aston moved squarely into Rutherford's orbit in atomic physics. Early in 1920, for example, Rutherford had told Bohr that «Aston gave a paper on isotopes in the laboratory the other day and J.J.T[homson] said he did not believe his results about chlorine. You can imagine that I enjoyed myself thoroughly between the two» ${ }^{77}$. Thomson

\footnotetext{
75. Rutherford, Ernest, to Bohr, Niels. 5 June 1922. Rutherford papers.

76. Aston, F. W. The Isotopes of Tin. Nature. 1922; 109: 813; Aston, F. W. The Mass-Spectrum of Iron. Nature. 1922; 110: 312; Aston, F. W. The Isotopes of Selenium and some other elements. Nature. 1922; 110: 664; Aston, F. W. Photographic plates for the detection of mass rays. Proceedings of the Cambridge Philosophical Society. 1925; 22: 548-554 (550).

77. Rutherford, Ernest, to Bohr, Niels. 18 February 1920. Rutherford papers.
} 
had been a sceptic about isotopes from the outset. And while his dissension from the Rutherford-Aston account of isotopes and the nucleus surely reflected his own prejudices and interests, it also emphasises the contingency and contestability of the new interpretation. Thomson's criticisms became public in early March 1921, when the Royal Society held a «Discussion on Isotopes» under the chairmanship of its President - Thomson himself. Rutherford waggishly reported the highlight of the meeting to Bohr: «There was a discussion on isotopes at the R[oyal] S[ociety] yesterday. JJT led off followed by Aston, Soddy \&c. I believe the former rather threw doubt on isotopes in a vague way because they did not fit well with his conceptions of atoms and the forces therein» ${ }^{78}$.

Rutherford's evident schadenfreude arose from the fact that Thomson made a series of detailed criticisms of the mass-spectrograph itself and of Aston's (and, by implication, Rutherford's) interpretation of its results, and from Aston's inability to parry them. It also arose from Rutherford's own views on Aston's intellectual and scientific qualities. Important evidence on this point comes from a testimonial written about this time by Rutherford for Aston, who was evidently being considered for a Research Fellowship, probably at Trinity College, Cambridge. According to Rutherford «the recent important experiments of Dr. Aston are the direct outcome of the development of the positive ray method by Sir J.J. Thomson [with] whom he first gained that knowledge that has made further experimental advances possible». Noting his opinion that «the direct proof obtained by Dr. Aston of the variations in the mass of many of the ordinary elements is of fundamental importance and marks a definite stage in the advance of our knowledge of the constitution of the elements», Rutherford judged that Aston had «shown that he not only is a skilled experimenter (...) with unusual powers of technique but has displayed insight and judgement in deriving a powerful method (...) to accomplish his purpose» ${ }^{79}$.

Rutherford's careful choice of language is revealing. The words under erasure in his draft de-emphasise Aston's creativity and originality, and suggest instead his ability to work towards a pre-defined goal. Indeed, Rutherford then conceded this point directly. Damning with faint praise and subtle

78. Rutherford, Ernest, to Bohr, Niels. 4 March 1921. Rutherford papers.

79. Rutherford's draft testimonial for Aston. Undated [probably 1920]. Rutherford Papers. PA364. 
modulation, he commented that «Aston's discovery, while not in a sense so fundamental or far-reaching as Moseley's proof of the relation between the properties of an element and its atomic number, is undoubtedly one of the finest pieces of work that has been done for some time in physics». But then came the killer punch: «While I think all could agree that Aston is an experimenter of unusual powers in my opinion he is not strong on the philosophical or speculative side and in that respect differs from the type of physicist and while an interesting and clear speaker on the subjects [connected with his work] may not have the broad capacity and knowledge of theory required of the best teachers» ${ }^{80}$. Contrast this, for example, with Rutherford's nomination (with his Cavendish colleague Charles Wilson, himself Nobel laureate in Physics in 1927) of Chandrasekhara Raman for the Prize in 1928, in which they specifically noted that Raman was «a man strong on both the theoretical and experimental side» ${ }^{81}$, and we begin to have a sense of the virtues that these particular nominators sought in a would-be Nobel prizewinner.

It is clear then that Rutherford did not have a high regard for Aston's capacities as a creative interpretative physicist, but saw him as an outstanding experimentalist best suited to working out the ideas of others. For this reason he was happy to offer him room to continue his work in the Cavendish, and thought that he would be a useful ornament to the laboratory, Trinity College and Cambridge University. But Aston was no research leader or innovator - and therefore, to Rutherford, himself a significant Nobel nominator, not worthy of a Nobel Prize. Now, however, having been savaged in public by the President of the Royal Society, Aston and his allies were obliged to rebut Thomson's criticisms in order to maintain the credibility of the mass-spectrograph, a major plank underpinning Rutherford's programme. Needing to rebut Thomson's analysis, but lacking the analytical machinery to do so, exactly as Rutherford's testimonial suggests, he called upon the expert assistance of Ralph Fowler, Cambridge mathematical physicist, Rutherford's housetheoretician and, incidentally, his son-in-law. Aston and Fowler published a joint paper in which Fowler demolished Thomson's assumptions and countered mathematics with mathematics to show «that the theory and

80. Rutherford, n. 79.

81. Quoted in Singh; Riess, n. 11, p. 276. 
practice of this form of mass spectrograph are in very satisfactory agreement, and present no anomalous and disturbing discordances» ${ }^{82}$.

Bolstered by constant modifications in technique and almost total theoretical and interpretative support from Rutherford and his allies, Aston and the mass-spectrograph maintained a continuous flow of results over the following months. And while Thomson remained sceptical, Rutherford and other audiences in the wider world -chemists, spectroscopists and astronomers - assimilated and appropriated Aston's results for their own ends. Recognition and honours flowed his way as the world outside the Cavendish Laboratory read and assimilated his research reports. Notwithstanding Rutherford's doubts about his intellectual strengths, he was elected a Fellow of Trinity College in June 1920, and a Fellow of the Royal Society in $1921^{83} .1922$ saw publication of Aston's monograph Isotopes, in which he summarised his work to date and in the preface of which he acknowledged «timely criticism and unfailing assistance» from Cambridge mathematical physicist C.G. Darwin and - no surprise, perhaps- R.H. Fowler ${ }^{84}$. An American lecture tour followed in March, and Aston and Soddy were reunited at the Solvay Chemistry Congress in Brussels in April 1922 where they put up a united front in affording accounts of their work which dovetailed nicely with each other and now presented a picture of a subject elevated from «the position of an obscure development in connection with radio-chemistry to one of universal and startling significance» ${ }^{85}$.

82. Aston F. W.; Fowler, R. H. Some problems of the mass-spectrograph. Philosophical Magazine. 1922; 43: 514-528 (521).

83. I thank Jonathan Smith of Trinity College Library, Cambridge, for information about Aston's election at Trinity. Aston's proposers for election to the Royal Society were Ernest Rutherford, J.J. Thomson, William Pope, J.W. Nicholson, O.W. Richardson, F. Soddy, Joseph Larmor, J.S. Townsend, F.A. Lindemann, C.T.R. Wilson and Frank Dyson.

84. Aston, n. 66, p. iii.

85. Soddy, F. W. Les Isotopes. In : Institut International de Chimie Solvay. Premier Conseil de Chimie. Bruxelles; 1922; Soddy, F. W. Rapports et Discussions sur Cinq Questions d'Actualité. Paris: Gauthier-Villars et Cie., 1925, p. 1-13 (2-3); Aston, F. W. La détermination des poids atomiques par la méthode des rayons positifs. In: Rapports et Discussions sur Cinq Questions d'Actualité. Paris: Gauthier-Villars et Cie., 1925, p. 23-56. On the background, see Nye, Mary Jo. Chemical explanation and physical dynamics: Two research schools at the first Solvay chemistry conferences, 1922-1928. Annals of Science. 1989; 46: 461-480. 


\section{The Nobel Prizes and the history of isotopes}

In late November 1922, the new evidential role of Aston's work and its role in Rutherford's research were publicly marked when he and Rutherford were awarded the Royal Society's Hughes and Copley medals respectively. Rutherford was cited for his early work on radioactivity, the now-unambiguous discovery of the nuclear atom and his recent work on atomic disintegration. The Society's President, now Charles Sherrington, noted that Aston's research on isotopes, though of recent vintage, had «already become classical», and emphasised «the great manipulative skill required to achieve these results as well as (...) the high scientific importance of the results themselves» ${ }^{86}$. By this time, it was widely known that both Aston and Soddy had been awarded Nobel Prizes for Chemistry. For both, the news from Stockholm set the seal on the string of accolades they had received over the previous months. For Aston and several others, however, the news was - as we have seen- more unexpected.

Though he pronounced himself «frightfully pleased» with it, Soddy seems to have heard of his prize initially via a congratulatory telegram from Rutherford and Lady Rutherford ${ }^{87}$. After confirmation and brief reflection, he wrote again to thank Rutherford and to acknowledge «the debt I owe you for the initiation into the subject of radioactivity in the old Montreal days» ${ }^{88}$. Soddy told Arrhenius that the Nobel award was «a most handsome acknowledgement of my share in the discovery of isotopes» ${ }^{89}$. A few days later, he told his fellow-radioactivist Georg Hevesy that the greatest value of the prize to him was that «as a verdict of an impartial jury, it is an international acknowledgement of the work of my students and myself» ${ }^{90}$. He wrote too to Aston to congratulate him on the 1922 award, and received the pithily economical reply «Equally delighted myself re 1921. Au revoir Stockholm» ${ }^{91}$. The mutual back-slapping notwithstanding, we can now

86. Address of the president, Sir Charles S. Sherrington, at the anniversary meeting, November 30, 1922. Proceedings of the Royal Society. 1923; A102: 373-388 (384-385 and 388).

87. Soddy, F. to the Rutherfords, 10 November 1922. Rutherford papers.

88. Soddy, F. to Rutherford, E. 10 November 1922. Rutherford papers.

89. Soddy, F. to Arrhenius. 14 November 1922. Arrhenius papers.

90. Soddy, F. to Hevesy. 17 November 1922. Hevesy papers, Niels Bohr Archive, Copenhagen. Soddy went on to congratulate Hevesy for his work with Brønsted on the separation of isotopes, a «notable achievement» which he ranked «next only to that of Aston in the last few years».

91. Aston, F. W. to Soddy, F. 11 November 1922. Soddy papers. 
understand why Rutherford would probably not even have considered nominating Aston, and indeed why he was surprised to find Aston's name listed alongside those of Soddy, Bohr and Einstein on the morning of 10 November 1922. So who did nominate Aston, and how can we understand the Nobel Chemistry Prize committee's decision?

Neither Soddy nor Aston had been considered by the Nobel Chemistry Committee in 1921, most of the nominations going to Nernst or J.M. Eder. As Elisabeth Crawford and Diane Barkan have shown, Arrhenius, who had long obstructed an award to Nernst was unable to deflect support any longer, and Nernst received the reserved 1920 Chemistry award in 1921, perhaps leaving the way open for a fresh approach the following year ${ }^{92}$. For the 1922 award, despite his occasional ambivalence towards his former co-worker, Rutherford repeated the nomination for Soddy he had made in 1917, 1918 (when W. Schlenck had also nominated Soddy) and 1919. Aston was nominated for the 1922 Chemistry Prize by Emil Baur, Professor of Physical Chemistry at the Technische Hochschule, Zurich; this was his sole nomination for this award, most of the nominations for the 1922 Chemistry Prize being for Theodor Curtius, Gustav Tammann, Georges Urbain or Philippe-Auguste Guye. Bohr was the overwhelming choice of the nominees for the 1922 Physics prize, among them W.L. Bragg, Max von Laue, Millikan, Planck, Röntgen and Rutherford. Interestingly, Aston was nominated for the 1922 Physics prize by Leo Graetz (Professor of Physics at the University of Munich), Theodore Richards (the Harvard atomic weight specialist, who suggested dividing the prize between Aston and Millikan) and Charles Doolittle Walcott, former Director of the U.S. Geological Survey and since 1907 Secretary of the Smithsonian Institution of Washington, who rather dissipated the impact of his nomination by suggesting division of the prize between Charles Greeley Abbott, Aston, William Coolidge, George Hale and Robert Millikan.

What is conspicuous from the foregoing is that Soddy and Aston (and particularly the latter) were by no means overwhelming front-runners for the 1921 and 1922 awards in either Chemistry or Physics. This in itself is not unusual: as Friedman points out, «rarely did the candidate who received the most nominations get the prize» ${ }^{93}$. What is surprising, however, is

92. Barkan, Diana. Simply a matter of chemistry? The Nobel Prize for 1920. Perspectives on Science. 1994; 2: 357-395.

93. Friedman, n. 8, 1989, p. 75. 
that no-one who knew him well or who had direct acquaintance with his work nominated Aston for a Nobel Prize, indicating a radical difference in perspective within and without the complex web of personal loyalties and enmities constituting the small community of radioactivity and atomic researchers. In some ways, this situation was, ironically, the very opposite of the interest-driven nomination along nationalist or personal lines which has been taken to characterise many other prize awards in this period. While it is not my purpose here to give a detailed account of the Nobel Chemistry committee's decision, it is highly likely that Arrhenius's well-known role as a promoter of atomic research in the Nobel Prize committees was continued, and tied in to the disciplinary politics of radioactivity. In 1919, for example, Arrhenius arranged for Soddy to succeed British chemist William Crookes as a foreign member of the Swedish Royal Academy of Sciences in 1919. In the summer of 1922, just as the Nobel Chemistry committee was arriving at its decision to honour Soddy and Aston, Arrhenius invited Rutherford to lecture in Stockholm ${ }^{94}$. And, significantly, Arrhenius had attended the 1922 Solvay Chemistry meeting, and contributed to the discussion of the definition of chemical elements following Aston's paper, enthusiastically supporting Aston's conclusions and specifically aligning himself with Aston «as a physicist and as a chemist» ${ }^{95}$.

While Arrhenius's role was evidently central, it is also clear that the Nobel Chemistry Committee considered the work of Soddy and Aston together, the one justifying the other. In so doing they accepted and legitimated a retrospective account of the «discovery» of isotopes which drew on that which the two scientists themselves and their allies had carefully elaborated over the preceding months. Indeed, in some ways the framing of the Nobel award went beyond even Aston and Soddy's historical fabulations. In his presentation speech for Aston, for example, Söderbaum ranged across a scientific landscape reaching from «the philosophers of ancient Hellas», "the minds of the alchemists of the Middle Ages and Renaissance» through Robert Boyle to Prout, Berzelius, Stas, Theodore Richards and, eventually, to Aston's corner of the Cavendish Laboratory in 1919, to claim that through the discovery of isotopes «a riddle which for over a hundred years has engaged chemical research has attained its solution,

94. Soddy, F. to Arrhenius. 16 June 1919. Arrhenius papers; Rutherford, E. to Arrhenius. 24 August 1922. Arrhenius papers.

95. Institut International de Chimie Solvay, n. 85, p. 61. 
and a surmise which for thousands of years has floated before the human mind has thereby been confirmed» ${ }^{96}$. Meta-neon and the true nature of scientific process had quietly dropped out of the picture, and the work on isotopes was now triumphantly cited as a vindication of the RutherfordBohr nuclear model of the atom - concurrently celebrated, of course, by the Nobel Physics committee in its 1922 award to Bohr.

The retrospective crafting of the history of isotopes should not surprise us: historians of science are very aware of the importance of such strategies in securing assent and legitimacy for scientific work. Yet two points are worthy of comment. First, this construction of scientific history was not merely the partisan work of the scientists themselves: it was endorsed and even extended by the «impartial jury» of the Nobel institution. In terms of its relationship to the history and historiography of the physical sciences more broadly, the framing of the Nobel Chemistry awards for 1921 and 1922 at best obscured and at worst falsified for contemporaries the nature of Aston's scientific achievement. For later historians, this has had the unfortunate consequence of providing an apparently authoritative account of the discovery of isotopes which bore little relation to the actual sequence of events and which, moreover, seemed to provide an authentic and compelling ratification of the canonical account of the history of nuclear science. No troubling questions about the contingency of the isotope interpretation of matter need then be raised.

Second, while the Nobel Chemistry committee's ratification of Aston's work laudably rested on the merits of the achievement itself (however retrospectively defined and framed), it simultaneously created a problem for Rutherford and the others who had effectively appropriated Aston's work, interpreted it for him and constructed the scientific programme which underlay the Nobel award. Aston's colleagues overcame their surprise by making a virtue of necessity. Though reporting of the two awards in Britain was distinctly muted, being largely overshadowed by Armistice Day and an impending General Election, The Times carried a photograph of Aston and Soddy on the dais in Stockholm at the Music Conservatory in Stockholm as they waited to receive their prizes ${ }^{97}$. Public reaction may have been indifferent, but when he returned to the Cavendish Laboratory,

96. Söderbaum, H. G. Presentation Speech to F. Soddy. In: Nobel Lectures in Chemistry, 1922-1941 Amsterdam: Elsevier; 1966, p. 3-6 (5-6).

97. Nobel Prizes presentation at Stockholm. The Times. 12 December 1922: 11. 
Aston's fellow-researchers were jubilant at what they now saw as a confirmation of their model of the heroic, individual, experimental genius. At the annual dinner of the Cavendish Physical Society in February 1923 they serenaded him to the tune of «The Highly Respectable Gondolier» from «The Gondoliers». The first and last verses $\operatorname{ran}^{98}$ :

«Since J.J. on the game began,

By analysing Neon,

Many a speculative man

Had isotopic thoughts which ran

Beyond a paper's rightful span,

So this did all agree on -

It needs a man both strong and stout

These isotopes to sever

Of this there is no possible doubt,

No probable, possible, shadow of doubt,

No possible doubt whatever (...)

Now Christmas time was drawing near,

And as Nobel prize winner,

For Stockholm soon he had to clear,

(Then he followed the trade of a mountaineer),

And now we're all glad we've got him here

To cheer him at our Dinner

«He's a jolly good fellow!» Then let us shout

In louder tones than ever -

Of this there is no possible doubt,

No probable, possible, shadow of doubt,

No possible doubt whatever».

Clearly, Aston's sister Helen was not alone in basking in reflected glory. The students and staff of the Cavendish Laboratory perhaps appreciated the social and cultural meaning of the Nobel Prize in a rather different way than the Nobel Prize committee or, indeed, the wider world.

98. Isotopes. Lyrics by Stoner, E.C. sung to the tune «The highly respectable gondolier» (The gondoliers) at the Cavendish Physical Society Dinner. 24 February 1923. In: Post-Prandial Proceedings of the Cavendish Physical Society. Cambridge: Bowes \& Bowes; 1926. 
Dynamis 2009; 29: 131-165

\section{Conclusion}

In the years after the Nobel Prize, Aston continued to develop the massspectrograph, with more accurate versions of the device following in 1927 and 1937. He succeeded Soddy as reporter on «Radioactivity» (now redesignated «Sub-atomic Phenomena and Radioactivity») for the Chemical Society's Annual Reports on Progress in Chemistry in 1923, and turned the report into a vehicle for the latest results from the Cavendish Laboratory ${ }^{99}$. He also became a leading member of the reconstituted International Committee on Atomic Weights under the auspices of the International Union of Pure and Applied Chemistry, in which he became the authority on isotopes ${ }^{100}$. With the weight and prestige of the Nobel Prize behind him and his almost single-handed control of mass-spectrography until the 1930s, Aston became most closely identified among the broader scientific public with isotopes - he contributed the article on the subject to the 1929 edition of Encylopaedia Britannica, for example ${ }^{101}$. While he was an authority on the production of mass-spectrographic data concerning isotopes, however, he continued to rely entirely on Rutherford and other Cambridge colleagues for the theoretical framework within which to situate his own work. Indeed, the motivation for the construction of his second and third mass-spectrographs came partly from his own characteristic drive for ever-greater accuracy for its own sake, and partly from the demands of Rutherford's programme in nuclear physics which demanded more and more precise numbers for the calculation of nuclear properties ${ }^{102}$. It is also noteworthy that Aston never took up his right to nominate for the Nobel Prizes, and played little part in wider ideological and epistemological debates about the relations between physics and chemistry or between experiment and theory which shaped those sciences in the 1920s and 1930s.

99. Aston, F.W. Sub-Atomic phenomena and radioactivity. In: Chemical Society. Annual Reports on the Progress of Chemistry. 1923; 19: 267-288. During the 1920s, Aston also used the biennial report to offer partisan comment on the Cambridge-Vienna controversy over the results and interpretation of nuclear disintegration experiments.

100. Aston, F. W. Report of the International Committee on Chemical Elements, 1923. Journal of the American Chemical Society. 1923; 45: 867-874; Fennell, Roger. History of IUPAC, 19191987. Oxford: Blackwell Science; 1994, p. 35-38.

101. Aston, F. W. Isotopes. Encyclopaedia Britannica, 13th Edition. London and New York: Encyclopaedia Britannica; 1929, vol. 12, p. 726-730.

102. See, for example, Aston, F.W. A New mass-spectrograph and the whole number rule (Bakerian Lecture). Proceedings of the Royal Society. 1927; A115: 487-514. 
Not least on the strength of his Nobel Prize, then, Aston was catapulted into a position as a public authority on atomic physics. Yet the mismatch between what had been the collective underpinning of his achievement and the individualistic nature of the recognition and reward continued to create tensions which Aston and his colleagues had to negotiate and re-negotiate. By contrast, the Nobel Prize did little for Soddy. He had been widely expected to develop a serious research programme in radioactivity after his appointment as Professor of Inorganic Chemistry at Oxford in 1919, but these expectations remained unfulfilled ${ }^{103}$. Conflict with colleagues and administrators within Oxford University — he called himself «a catfish among the $\operatorname{cod}{ }^{104}$ - the demands of institution-building and his growing interest in economic questions and the social relations of science meant that Soddy's energies were largely directed away from scientific research. He made no further contributions to the experimental study of the atom's constitution, although he remained a trenchant and well-read commentator on matters atomic ${ }^{105}$. Already in the 1930 s, Soddy was leaving the bonhomie of the Nobel Prizewinners' club behind as he began to critique what he saw as the false construction of atomic and nuclear history by physicists - especially those associated with the Cavendish Laboratory. As he wrote to one correspondent, «the sort of legend that grows up in connection with the history of discoveries in our own time with which we are completely familiar makes one hesitate to believe there can be any truth in history as recorded by the historian at all, a thought that explains much». He might well have been thinking of the collective construction of Francis Aston as a heroic discoverer when he wrote that « $[\mathrm{s}] \mathrm{o}$ easy is it to fall into the error of thinking that things which look obvious after a discovery were just as obvious before» 106 .

In one sense, Soddy's reflections were his response to his marginalisation in the ongoing project to map the nature of the atom. After World War II, he would forthrightly condemn the «falsification» of scientific history

103. Cruickshank, A. D. Soddy at Oxford. In Kauffman, G. B., ed. Frederick Soddy. Early pioneer in radiochemistry. Dordrecht, Boston and Lancaster: D. Reidel; 1986, p. 157-170 (160).

104. Howorth, M. Pioneer research on the atom. Rutherford and Soddy in a Glorious Chapter of Science. The Life Story of Frederick Soddy. London: New World Publications; 1958, p. 227236.

105. Soddy's ever-popular book The Interpretation of Radium went into a fourth edition in August 1920, and was again reprinted in May 1922. See Cruickshank, n. 103.

106. Soddy, F. to Noyes, W. A. 22 February 1936. Soddy papers, Bodleian Library, Oxford, f.233. 
by a self-serving «claque» of Rutherford's acolytes. At the fourth conference of Nobel Prizewinners at Lindau (Bodensee) in June 1954, he railed against the mathematical physicists whom he saw as having taken over his beloved subject of radioactivity ${ }^{107}$. As I indicated at the outset, Soddy had a point, as postwar physicists constructed a linear, teleological history of nuclear physics to locate the agency underpinning nuclear weapons firmly in nature. Yet Soddy, perhaps because of his own status as a Nobel Laureate - or perhaps even because he still harboured the illusion that the Nobel Committees constituted an «impartial jury»- missed a broader point. As the example not just of Aston's but of Soddy's own award indicated, the Nobel Prizes have been central to the creation and perpetuation of myths about science which serve to obscure, rather than advance, understanding of scientific process. Soddy, one might say, was the victim of his own success while Aston was the beneficiary.

More broadly, this argument should encourage us to integrate critical analyses of the Nobel Prizes into other aspects of the history and historiography of science. There is always the danger that, taken within a narrow focus, the Nobel Prizes become objects of study in-and-of themselves. Yet, as Helge Kragh has argued, in the early twentieth century physical chemistry and radiochemistry bridged the boundaries between physics and chemistry and provided many of the resources for re-shaping both fields ${ }^{108}$. For those who would challenge a retrospectively-defined and legitimated historiography of atomic physics and chemistry, a detailed understanding of the politics and ideology of the Nobel Prizes and the debates of the Nobel Physics and Chemistry Committees are extremely useful resources for understanding the fluidity and contingency of those boundaries in the early twentieth century.

107. Soddy, F. to Howorth, Muriel. 8 September 1953. Soddy papers, MS Eng. Misc. b.170; Soddy, F. The wider aspects of the discovery of atomic disintegration, contrasting the experimental facts with the mathematical theories. Soddy papers, MS Eng. Misc. b.172.

108. Kragh, Helge. Conceptual changes in chemistry: The notion of a chemical element, ca. 19001925. Studies in History and Philosophy of Modern Physics. 2000; 31 (4): 435-450. 